\section{А.В. Никонорова}

Alla Nikonorova

\section{ГОСУДАРСТВЕННОЕ СТИМУЛИРОВАНИЕ РАЗВИТИЯ ИННОВАЦИОННОЙ ИНФРАСТРУКТУРЫ РЕГИОНА}

Аннотация. В статье рассмотрены вопросы государственного стимулирования инновационной деятельности в регионе. Проведен анализ нормативно-правовых документов на предмет регулирования экономической деятельности отечественных предприятий, работающих на территории Причерноморья. Также в статье выделень наиболее приоритетные и перспективные направления государственного стимулирования в области развития инновационной инфраструктуры региона. Особое внимание в статье уделено реализации целевых программ и их влиянию на повышение качества предоставляемых услуг и уровень жизни местного населения.

Ключевые слова: инновационная инфраструктура, управление, государственное стимулирование, целевые программы, активизация экономической деятельности, Причерноморье.

\title{
STATE STIMULATION OF INNOVATIVE INFRASTRUCTURE DEVELOPMENT IN THE REGION
}

\begin{abstract}
Annotation. The article reveals the questions of state stimulation of innovative activity in the region. The analysis of normative and legislative documents in the field of economic activity regulation of domestic enterprises operating on the Black Sea region is made. The article also highlights the most important and perspective directions of state stimulation in development of innovative infrastructure of the region. Special attention is paid to implementation of target programs and their impact on improving quality of provided services and standard of living of resident population.

Keywords: innovative infrastructure, management, state stimulation, aim programs, improvement of economic activity, the Black Sea region.
\end{abstract}

Стимулирование развития инновационной инфраструктуры региона не может реализовываться вне влияния государства и реализации государственной инновационной политики.

Разработка четкой и результативной инновационной политики государства представляет собой сложную задачу, успешное решение которой носит принципиальный характер. В современном мире создание условий для реализации имеющегося потенциала и внедрение инновационных технологий является залогом успешного развития страны, отдельных регионов, предприятий.

В экономиках различных стран степень вмешательства государства в процессы управления характеризуются достаточной подвижностью: периоды дерегулирования приходят на смену усиленному государственному регулированию, что зависит от степени государственного вмешательства. Усиление регулирующей роли государственных структур зачастую является естественной реакцией на утрату управляемости, потерю стабильности социально-экономической системы [10]. В Российской Федерации степень влияния государства на процессы управления также значительно изменялось с течением времени. В настоящий период времени ведутся активные дискуссии относительно необходимости вмешательства государства в различные сферы деятельности.

При том, что в создании и активном внедрении инновационных технологий заинтересованы в том числе и коммерческие организации, роль государства, регламентирующего и контролирующего данный процесс на стратегическом уровне, огромна.

(C) Никонорова А.В. 
Для создания эффективно работающей инновационной системы в Российской Федерации введен в действие ряд нормативно-правовых актов, регулирующих экономические аспекты инновационной деятельности [13]. Среди них особым образом следует выделить нижеперечисленные документы.

1. Распоряжение Правительства РФ от 08.12.2011 № 2227-р «Об утверждении Стратегии инновационного развития Российской Федерации на период до 2020 г.» [8].

2. Распоряжение Правительства РФ от 17.11.2008 № 1662-р (ред. от 10.02.2017) «О Концепции долгосрочного социально-экономического развития Российской Федерации на период до 2020 года» [6].

3. Постановление Правительства РФ от 15.04.2014 № 316 (ред. от 17.08.2017) «Об утверждении государственной программы Российской Федерации «Экономическое развитие и инновационная экономика» [5].

4. Распоряжение Правительства РФ от 05.09.2011 № 1538-р (ред. от 26.12.2014) «Об утверждении Стратегии социально-экономического развития Южного федерального округа до 2020 г.» [7].

5. Федеральный закон от 23.08.1996 № 127-Ф3 (ред. от 23.05.2016) «О науке и государственной научно-технической политике» [1].

6. Федеральный закон от 22.07.2005 № 116-Ф3 (ред. от 03.07.2016) «Об особых экономических зонах в Российской Федерации» [2].

7. Федеральный закон от 29.11.2014 № 377-ФЗ (ред. от 19.12.2016) «О развитии Республики Крым и города федерального значения Севастополя и свободной экономической зоне на территориях Республики Крым и города федерального значения Севастополя» [3].

8. Постановление Правительства РФ от 05.12.2001 № 848 «О Федеральной целевой программе «Развитие транспортной системы России (2010-2021 гг.)» [4].

В перечисленных выше документах предусмотрены мероприятия, нацеленные как на инновационное развитие страны в целом, так и отдельных регионов, включая российскую часть Причерноморья. Несмотря на то, что они регламентируют различные сферы деятельности, их анализ позволяет выделить в формировании направлений инновационной государственной политики для Причерноморья следующие общие тенденции:

- внедрение инновационных технологий;

- активизация инновационной деятельности предприятий;

- развитие человеческого капитала;

- сохранение экосреды.

Устойчивое и успешное экономическое развитие российского Причерноморья напрямую зависит от реализации конкретных мероприятий.

Особым образом следует выделить тот факт, что многие нормативные акты, регламентирующие инновационную деятельность в Российской Федерации, охватывают период до 2020 г.

Таким образом, в ближайшее время должны быть разработаны для принятия новые нормативные документы для последующего этапа, что подчеркивает актуальность затрагиваемой в настоящей статье тематики.

Российское Причерноморье значительным образом отличается от остальных частей страны, оно имеет свои климатические особенности. В связи с этим весьма закономерно, что, обладая уникальными для нашей страны ресурсами, Южный федеральный округ, а также республика Крым занимают по уровню и темпам развития туристической и санаторно-курортной сфер лидирующие позиции.

Благодаря естественным природно-климатическим условиям в Южном федеральном округе и на территории республики Крым уже в настоящее время сформировалась особая, отличная от других частей страны среда. Поддержание и развитие конкурентных преимуществ региона способствует не только увеличению его доходов за счет увеличения потока туристов и объема производимых товаров и услуг, но и гармонизации социально-экономических условий в стране в целом. 
Среднегодовая температура на территории Южного федерального округа, а также республики Крым значительно выше, чем в остальных регионах страны, что позволяет с меньшими затратами выращивать там качественную сельскохозяйственную продукцию.

Для российской части Причерноморья характерно и исключительно выгодное геополитическое и геоэкономическое положение, определяемое его выходом к морским транспортным коммуникациям, соединяющим Россию со странами Средиземноморского, Азово-Черноморского и Каспийского бассейнов [7].

Особую роль в развитии инновационного потенциала региона играет создание особых экономических зон, способствующих созданию условий для активизации экономической активности в регионе. Так, в соответствии с Ф3 от 24.11.14 № 377-Ф3 [3] на территории Республики Крым и города федерального значения Севастополе была создана свободная экономическая зона. Срок существования зоны определен в двадцать пять лет.

Проведенный анализ позволяет выделить в совершенствовании инфраструктуры Причерноморья следующие тенденции:

- развитие круглогодичных курортов с высоким уровнем обслуживания;

- развитие рекреационных зон;

- создание на территории Крыма условий для производства сельскохозяйственной продукции в рамках реализации программы импортозамещения;

- развитие транспортной сети;

- развитие портов.

Черное море омывает берега Абхазии, Болгарии, Грузии, России, Румынии, Турции и Украины. В связи с этим полезным и целесообразным может быть изучение и рациональное применение успешного зарубежного опыта в области создания и развития деятельности инновационно-технологических центров, особых экономических зон, вузов, научно-исследовательских институтов, технологических парков и других организаций, формирующих в регионе инновационную инфраструктуру.

Для повышения активности и целостности осуществления конкретных мероприятий в стране разрабатываются и реализуются различные целевые программы, призванные активизировать экономическую деятельность в отдельных областях. Так, например, было принято Постановление Правительства РФ от 15.04.2014 № 316 «Экономическое развитие и инновационная экономика», целью которого является создание благоприятного предпринимательского климата и условий для ведения бизнеса, повышение эффективности государственного управления и инновационной активности бизнеса [5].

Для исполнения поставленной стратегической цели необходимо предусмотреть ряд ключевых задач, выполнение которых повысит социально-экономическую эффективность проводимых мероприятий [14].

Такими задачами являются:

- создание условий, способствующих привлечению инвестиций в экономику региона и Российской Федерации в целом;

- формирование экономики знаний и высоких технологий;

- повышение доступности и качества государственных и муниципальных услуг;

- защита и развитие конкуренции на товарных рынках;

- сокращение избыточного вмешательства государства в деятельность хозяйствующих субъектов;

- развитие малого и среднего предпринимательства;

- обеспечение организаций народного хозяйства Российской Федерации эффективными в современных условиях управленческими кадрами;

развитие системы государственного стратегического управления;

- соблюдение при реализации тарифной политики баланса интересов субъектов естественных монополий и потребителей их товаров (услуг); 
- совершенствование сбора, обработки и предоставления статистической информации;

- совершенствование государственной политики в сфере земельных отношений.

В качестве ожидаемого результата от реализации этой Программы в области развития инновационной инфраструктуры следует выделить увеличение доли организаций, осуществляющих технологические инновации, в общем числе организаций с 9,1 \% в 2012 г. до 11,7 \% в 2020 г. Инновационная инфраструктура направлена на обслуживание инновационной деятельности, положительным фактором ее создания является то, что она позволяет обеспечивать непрерывность инновационного цикла, способствует созданию условий для более упрощенного создания, внедрения и использования инноваций.

С целью активизации экономических процессов в регионе необходимо применять новые технологии управления. Так, например, создание в экономике региона кластеров, в которых концентрируются ресурсы государства, направленные как на поддержку самостоятельного бизнеса, функционирующего в отдельных секторах, так и отрасли в целом, может стать эффективным инструментом повышения экономической активности в России. Экономический рост позволяет создавать и реализовывать государственные программы, нацеленные на решение важнейших социальных проблем [15].

Следует отметить, что отличительной особенностью современного развития инновационной деятельности в мировой экономике в целом является тот факт, что вложения в науку и создание новых технологий не выступают непременной обязанностью государства.

Зачастую хозяйствующими субъектами, заинтересованными в разработке и внедрении инновационных технологий выступают коммерческие организации. В качестве положительной черты их деятельности следует выделить то, что бизнес, по сравнению с государственными институтами, обладает большей мобильностью, оперативностью принятия управленческих решений и способностью к генерации инноваций [11]. Однако, современная бизнес-среда характеризуется изменчивостью, которая носит всеобъемлющий характер [9]. Это приводит к тому, что разработки, реализуемые коммерческими организациями нацелены на краткосрочное получение максимальной прибыли, а не получение фундаментальных знаний. Финансирование фундаментальной науки по-прежнему осуществляется только государством.

Чтобы стимулировать дальнейший приток частного капитала в реализацию государственно значимых инфраструктурных проектов, необходимо двигаться в двух ключевых направлениях: совершенствовать законодательство и снижать долгосрочные риски инвестирования [12].

На территории российского Причерноморья сконцентрированы значительные и разнообразные ресурсы, рациональное применение которых способно положительным образом сказаться на общероссийских экономических показателях. Однако в настоящее время его социально-экономический потенциал используется недостаточно.

В Российской Федерации принят целый ряд законов, направленных на стимулирование инновационной деятельности и имеющих целью активизацию экономических отношений в Причерноморье. Анализ существующей нормативной базы, регламентирующей экономическое инновационное развитие Причерноморья позволяет сделать вывод о необходимости разработки для последующих периодов времени программ, предусматривающих более целостное развитие данного региона. Южный федеральный округ и Республика Крым обладают схожими ресурсами, климатическими, геополитическими и геоэкономическими показателями. Реализация аналогичных мероприятий на всей территории российской части Причерноморья позволит привести, в конечном итоге, к экономии за счет эффекта масштаба, а отсутствие такого целостного подхода к развитию юга Российской Федерации препятствует его гармоничному развитию.

Осуществление тщательно продуманных мероприятий при поддержке государства создает в современных условиях усиления конкуренции основу для дальнейшего развития региона, способствует реализации его инновационного потенциала. 


\section{Библиографический список}

1. Федеральный закон от 23.08.1996 № 127-Ф3 «О науке и государственной научно-технической политике» (ред. от 23.05.2016) [Электронный ресурс]. - Режим доступа: Справочная правовая система «КонсультантПлюс» (дата обращения: 01.12.2017).

2. Федеральный закон от 22.07.2005 № 116-Ф3 «Об особых экономических зонах в Российской Федерации» (ред. от 03.07.2016) [Электронный ресурс]. - Режим доступа: Справочная правовая система «КонсультантПлюс» (дата обращения: 01.12.2017).

3. Федеральный закон от 29.11.2014 № 377-Ф3 «О развитии Республики Крым и города федерального значения Севастополя и свободной экономической зоне на территориях Республики Крым и города федерального значения Севастополя» (ред. от 19.12.2016) [Электронный ресурс]. - Режим доступа: Справочная правовая система «КонсультантПлюс» (дата обращения: 01.12.2017).

4. Постановление Правительства РФ от 05.12.2001 № 848 «О Федеральной целевой программе «Развитие транспортной системы России (2010-2021 гг.)» (ред. от 20.09.2017) [Электронный ресурс]. - Режим доступа: Справочная правовая система «КонсультантПлюс» (дата обращения: 01.12.2017).

5. Постановление Правительства РФ от 15.04.2014 № 316 об утверждении государственной программы Российской Федерации «Экономическое развитие и инновационная экономика» [Электронный ресурс]. - Режим доступа: Справочная правовая система «КонсультантПлюс» (дата обращения: 01.12.2017).

6. Распоряжение Правительства РФ от 17.11.2008 № 1662-р «О Концепции долгосрочного социально-экономического развития Российской Федерации на период до 2020 г.» [Электронный ресурс]. - Режим доступа: Справочная правовая система «КонсультантПлюс» (дата обращения: 01.12.2017).

7. Распоряжение Правительства РФ от 05.09.2011 № 1538-р «Об утверждении Стратегии социально-экономического развития Южного федерального округа до 2020 г.» [Электронный ресурс]. - Режим доступа: Справочная правовая система «КонсультантПлюс» (дата обращения: 01.12.2017).

8. Распоряжение Правительства РФ от 08.12.2011 № 2227-р «Об утверждении Стратегии инновационного развития Российской Федерации на период до 2020 г.» [Электронный ресурс]. - Режим доступа: Справочная правовая система «КонсультантПлюс» (дата обращения: 01.12.2017).

9. Веселовский, М. Я. Инновационная деятельность и стратегии ее развития в современных условиях России / М. Я. Веселовский, А. В. Никонорова // Инновационное развитие России: условия, противоречия, приоритеты. Материалы IX Международной научной конференции. Часть 2. - М. : «Новые печатные технологии», 2013. - 448 с.

10. Веселовский, М. Я. Формирование конкурентных преимуществ российских предприятий в условиях экономической нестабильности: коллективная монография / М. Я. Веселовский, А. В. Федотов., В. Я. Вилисов, М. А. Меньшикова [и др.]; под ред. М. Я Веселовского, И. В. Кировой. - М. : Научный консультант, 2017. - 276 с.

11. Морковкин, Д. Е. / Инновационное развитие экономики на основе использования механизмов государственночастного партнерства / Д. Е. Морковкин // Вестник РГГУ. Серия: Экономика. Управление. Право. - 2015. № 1. - С. 27-35.

12. Руденко, Л. Г. / Моделирование современного государственно-частного партнерства как института развития инфраструктуры поддержки малого предпринимательства / Л. Г. Руденко // Бизнес. Образование. Право. Вестник Волгоградского института бизнеса. - 2016. - № 3 (36). - С. 109-115.

13. Руденко, Л. Г. / Проблемные аспекты и прогноз инновационной активности России / Л. Г. Руденко // Вестник Московского университета им. С.Ю. Витте. Серия 1: Экономика и управление. - 2013. - № 4 (6). - С. $26-32$.

14. Шумаев, В. А. Развитие механизмов государственной социальной поддержки на региональном уровне / В. А. Шумаев, Д. Е. Морковкин, В. В. Ранюк // Вестник Самарского государственного экономического университета. - 2015. - № 7 (129). - С. 49-54.

15. Kiseleva N. V., Panichkina M. V., Klochko E. N., Nikonorova A. V., Kireev S. V. Creation of clusters of small enterprises of the region. International Journal of Economics and Financial Issues. 2016, Vol. 6, I. S2, pp. $294-297$.

\section{References}

1. Federal'niy zakon ot 23.08.1996 № $127-\mathrm{FZ}$ «O nauke I gosudarstvennoy nauchno-tekhnicheskoy politike» [Federal law of 22.07.2005 № 116-FZ «About science and state scientific and technical policy»] (edition 23.05.2016). Available at: Spravochnaja pravovaja sistema «Konsul'tantPljus» [ConsultantPlus legal reference system] (Accessed: 01 December 2017).

2. Federal'niy zakon ot 22.07.2005 № 116-FZ «Ob osobyh ekonomicheskih zonah v Rossiyskoy Federatsii» [Federal law of 22.07.2005 № 116-FZ «About special economic zones in the Russian Federation»] (edition 03.07.2016). Available at: Spravochnaja pravovaja sistema «Konsul'tantPljus» [ConsultantPlus legal reference system] (Accessed: 01 December 2017). 
3. Federal'niy zakon ot 29.11.2014 № 377-FZ «O razvitii Respubliki Krym I goroda federal'nogo znacheniya Sevastopolya i svobodnoy ekonomicheskoy zone na territoriyah Respubliki Krym I goroda federal'nogo znacheniya Sevastopolya» [Federal law of 29.11.2014 № 377-FZ «About the development of the Republic of Crimea and city of Federal importance Sevastopol and free economic zone on the territory of the Republic of Crimea and city of Federal importance Sevastopol»] (edition 19.12.2016). Available at: Spravochnaja pravovaja sistema «Konsul'tantPljus» [ConsultantPlus legal reference system] (Accessed: 01 December 2017).

4. Postanovlenie Pravitel'stva RF ot 05.12.2001 № 848 «O Federal'noy tselevoy programme «Razvitie transportnoy sistemy Rossii (2010-2021 gody)» [Resolution of the Government of 05.12.2001 № 848 «About the Federal target program «Development of transport system of Russia $(2010$ - 2021)»] (edition 20.09.2017) . Available at: Spravochnaja pravovaja sistema «Konsul'tantPljus» [ConsultantPlus legal reference system] (Accessed: 01 December 2017).

5. Postanovlenie Pravitel'stva RF ot 15.04.2014 № 316 ob utverzhdenii gosudarstvennoy programmy Rossiyskoy Federatsii «Ekonomicheskoe razvitie i innovatsionnaya ekonomika» [Resolution of the Government of 15.04.2014 № 316 about the ratification of the state program of the Russian Federation «Economic development and innovative economy»] (edition 17.08.2017). Available at: Spravochnaja pravovaja sistema «Konsul'tantPljus» [ConsultantPlus legal reference system] (Accessed: 01 December 2017).

6. Rasporyazhenie Pravitel'stva RF ot 17.11.2008 № 1662-p «O Kontseptsii dolgosrochnogo sotsial'no-ekonomicheskogo razvitiya Rossiyskoy Federatsii na period do 2020 goda» [Resolution Of The Government of 17.11.2008 № 1662-p «About the concept of long-term socio-economic development of the Russia№ Federation for the period until 2020»] (edition 10.02.2017). Available at: Spravochnaja pravovaja sistema «Konsul'tantPljus» [ConsultantPlus legal reference system] (Accessed: 01 December 2017).

7. Rasporyazhenie Pravitel'stva RF ot 05.09.2011 № 1538-p «Ob utverzhdenii Strategii sotsial'no-ekonomicheskogo razvitiya Yuzhnogo federal'nogo okruga do 2020 goda» [Resolution of the Government of 05.09.2011 № 1538-p «About the ratification of strategy of social-economic development of the Southern Federal district until 2020»] (edition 26.12.2014). Available at: Spravochnaja pravovaja sistema «Konsul'tantPljus» [ConsultantPlus legal reference system] (Accessed: 01 December 2017).

8. Rasporyazhenie Pravitel'stva RF ot 08.12.2011 № 2227-r «Ob utverzhdenii Strategii innovatsionnogo razvitiya Rossiyskoy Federatsii na period do 2020 goda» [Resolution of the Government of 08.12.2011 № 2227-r «About theratificationof strategy of innovative development of the Russiat Federation until 2020»]. Available at: Spravochnaja pravovaja sistema «Konsul'tantPljus» [ConsultantPlus legal reference system] (Accessed: 01 December 2017).

9. Veselovskiy M. Ya., Innovatsionnaya deyatel'nost' I strategii ee razvitiya v sovremennyh usloviyah Rossii [Innovative activity and strategies of its development in modern conditions of Russia]. Innovatsionnoe razvitie Rossii: usloviya, protivorechiya, prioritety. Materialy IX Mezhdunarodnoy nauchnoy konferentsii. Chast' 2 [Innovative development of Russia: conditions, contradictions, priorities. Proceedings of the IX International scientific conference]. Moscow, Novye pechatnye tekhnologii, 2013. $448 \mathrm{p}$.

10. Veselovskiy M. Ya. Formirovanie konkurentnyh preimushchestv rossiyskih predpriyatiy v usloviyah ekonomicheskoy nestabil'nosti: kollektivnaya monografiya [The formation of competitive advantages of Russian enterprises in conditions of economic instability: collective monograph]. Moscow, Nauchniy konsul'tant, 2017. 276 p.

11. Morkovkin D.E. Innovatsionnoe razvitie ekonomiki na osnove ispol'zovaniya mekhanizmov gosudarstvenno-chastnogo partnerstva [Innovative development of economy on the basis of the usage of state-private partnership mechanisms]. Vestnik RGGU. Seriya: Ekonomika. Upravlenie. Pravo [Bulletin of RSUH. Series: Economics. Management. Low]. 2015, I. 1, pp. 27-35.

12. Rudenko L. G. Modelirovanie sovremennogo gosudarstvenno-chastnogo partnerstva kak institute razvitiya infrastruktury podderzhki malogo predprinimatel'stva [Modeling of the modern public-private partnership as the institution for infrastructure development of small business support] Biznes. Obrazovanie. Pravo. Vestnik Volgogradskogo institute biznesa [Business. Education. Low. Bulletin of the Volgograd Institute of business]. 2016, I. 3 (36), pp. 109-115.

13. Rudenko L. G. Problemnye aspekty i prognoz innovatsionnoy aktivnosti Rossii [The problematic aspects and the forecast of innovative activity in Russia]. Vestnik Moskovskogo universiteta im. S. Yu. Vitte. Seriya 1: Ekonomika i upravlenie [Bulletin of Moscow Witte University. Series 1: Economics and management]. 2013, I. 4 (6), pp. 26-32.

14. Shumaev V. A. Razvitie mekhanizmov gosudarstvennoy sotsial'noy podderzhki na regional'nom urovne [The development of mechanisms of state social support at the regional level]. Vestnik Samarskogo gosudarstvennogo ekonomicheskogo universiteta [Bulletin of Samara state University of Economics]. 2015, I. 7 (129), pp. 49-54.

15. Kiseleva N.V., Panichkina M.V., Klochko E.N., Nikonorova A.V., Kireev S.V. Creation of clusters of small enterprises of the region. International Journal of Economics and Financial Issues. 2016, Vol. 6, I. S2, pp. 294-297. 